\title{
Close to Half of the Granulomatous Mastitis may be Tuberculosis Mastitis
}

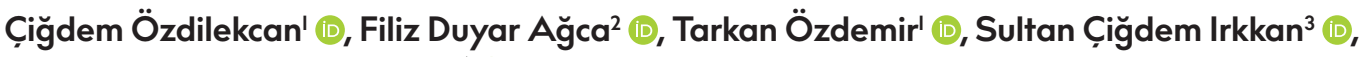 \\ Mustafa Hamidullah Türkkanı ${ }^{4}$ (D)
}

'Department of Pulmonology, University of Health Sciences Ankara Dr. Abdurrahman Yurtaslan Oncology Research and Training Hospital, Ankara, Turkey

2Department of Tuberculosis, Ankara 3rd Tuberculosis Dispensary, Ankara, Turkey

${ }^{3}$ Department of Pathology, University of Health Sciences Ankara Dr. Abdurrahman Yurtaslan Oncology Research and Training Hospital, Ankara, Turkey

${ }^{4}$ Department of Pulmonology, Sincan State Hospital, Ankara, Turkey

ORCID iDs of the authors: C..Ö. 0000-000I-5335-057I; F.D.A. 0000-0002-7132-8420; T.0̈. 0000-0002-9344-7586; S.C̣.I. 0000-000I-6442-74I5; M.H.T. 0000-0003-1503-7343.

Cite this article as: Özdilekcan Ç, Duyar Ağca F, Özdemir T, Irkkan SC̣, Türkkanı MH. Close to Half of the Granulomatous Mastitis may be Tuberculosis Mastitis. Cyprus J Med Sci 2020; 5(3): 217-20.

\section{BACKGROUND/AIMS}

Granulomatous mastitis (GM) is a chronic inflammatory benign disease that presents differential diagnostic difficulties as well as delays in diagnosis and treatment. The purpose of this study was to analyze the demographic and clinical findings of GM patients and describe the treatment outcomes after empirical antituberculosis treatment.

\section{MATERIAL and METHODS}

Forty-eight women with breast symptoms and a verified diagnosis of GM from the year 2014-2016 were evaluated. Of these patients, 20 of them who were nonresponders to the standard nonspecific treatment were included in the study. The study group consisted of these patients who were placed on antituberculosis treatment and followed-up to evaluate the treatment response.

\section{RESULTS}

The median age at time of diagnosis was 34 years (range, 2I-52). Of the total, 19 (95\%) women had unilateral and I (5\%) had bilateral breast involvement. Median time from the initiation of symptoms to the hospital admission was 7 days (range, I-364), and median time from admission to diagnosis was 4.5 months (range, I-120). Among the patients, $75 \%$ of them were admitted to the hospital in the first 60 days and $75 \%$ were admitted to three different health care centers until the definitive diagnosis. In addition, 4l.7\% (20/48) of patients could not be treated with nonspecific antiobitics and steroids but were treated empirically with anti-TB drugs. These patients had a complete response to the empirical antituberculosis treatment regimen.

\section{CONCLUSION}

Our results showed that $41.7 \%$ of GM may actually be TB mastitis according to our empirical treatment success results. Suspicion of breast tuberculosis is essential among pathologically verified GM patients who are especially clinically nonresponders to other treatment, with prolonged symptoms and recurrence. Empirical antituberculosis treatment can be recommended in pathologically proven GM patients especially in high-incidence regions for tuberculosis.

Keywords: Granulomatous mastitis, extrapulmonary tuberculosis, antituberculosis drugs, empirical treatment

\section{INTRODUCTION}

Granulomatous mastitis (GM) is a rare benign inflammatory disease of breast with an unknown etiology. However, tuberculosis (TB), sarcoidosis, mycotic and parasitic infections, and foreign body reactions have been accused as the etiology. It usually affects women of childbearing age. The condition presents with a hard palpable mass with skin erythema and lymph node enlargement. Nipple retraction, sinus formation, and breast atrophy may accompany to the findings (I). The clinical and radiological presentation of granulomatous mastitis usually mimics malignancy or infections (2). GM is usually unilateral; however, it may localize in all breast quadrants (3). Added to the difficulty in differential diagnosis of the condition, there has also been no consensus on the optimal treatment strategy for $\mathrm{GM}$, leading to a delay in the diagnosis 
and treatment of the disease. The aim of this retrospective study was to present the clinical and histopathological data and also to show the clinical outcomes of GM patients who received empirical antituberculosis treatment.

\section{MATERIAL and METHODS}

\section{Patient Selection}

Forty-eight women admitted to our outpatient clinics with breast pain complaints, palpable mass, skin erythema, and sinus formation meeting the histopathological criteria for GM were evaluated from the year 2014-2016. The patients underwent physical examination and ultrasonographic evaluation. Of the 48 patients who were histopathologically diagnosed as "granulomatous disease of the breast," 28 patients were treated successfully with antibiotics and/or steroids without recurrence and the remaining 20 women who had highly suspicious clinical and laboratory data for TB were included in the study. The TB contact, active disease history, treatment compliance, and treatment results of the patients were obtained from the dispensary reports. Also, details about the patient's symptoms and type of breast involvement were provided from the hospital records.

\section{Study Design}

This study was designed as a retrospective, single center, and non- interventional study.

\section{Ethical Situation}

Study was conducted in accordacne with the Declaration of Helsinki Guidelines. All the participants were provided written informed consent. The study was approved by the local medical expertise and education board of Ankara Oncology and Training Hospital (number: 17 date: 09.12.2017).

\section{Diagnostic Procedures and Data Collection}

The histopathological diagnosis was performed by ultrasound (US) guided tru-cut breast biopsy and the specimens were obtained from the ultrasonographically suspicious lesions.

\section{Main Points:}

- Granulomatous mastitis (GM) is a chronic inflammatory benign disease that presents differential diagnostic difficulties as well as delays in diagnosis and treatment.

- An important portion of GM may actually be TB mastitis according to our empirical treatment success results.

- Suspicion of breast tuberculosis is essential among pathologically verified GM patients who are especially clinically nonresponders to other treatments, with prolonged symptoms and recurrence.

- Clinical features with histopathologically proven GM can be a factor for the antituberculosis treatment choice especially in developing countries with especially high-incidence regions for tuberculosis.

- Although antituberculosis treatment is a safe and an effective choice in these group of patients, future molecular test approaches for the accurate diagnosis of GM is needed.
Demographic features, history of TB and close contact with TB patients, climacteric status, systemic and local symptoms, chest $X$-ray findings, duration of symptoms, duration of diagnosis, mammographic/ultrasonographic findings, diagnostic procedures, treatment strategies and outcomes, and side effects were recorded.

\section{Surgical or Biopsy Specimen Evaluation}

Histopathological examination of surgical or biopsy materials revealed "granulomatous disease of the breast" with noncaseating granuloma formation, destruction of the ductal structure, infiltration of the inflammatory cells, and micro-abscess formation. Tissue samples were examined using hematoxylin-eosin and Ehrlich Ziehl-Neelsen (EZN) for acid-fast bacilli.

\section{Treatment Strategy and Inclusion-Exclusion Criteria}

After nonspecific antibiotic therapy and steroid treatment was applied, anti-TB treatment was started for the non- responders. All the patients were treated with isoniazid (300 mgr/day), rifampicin (600 mgr/day), pyrazinamide (2000 mgr/day), and ethambutol (1500 mgr/day) according to the "National TB programme" recommended doses (4). The standard anti-TB treatment with four drugs was continued for 2 months initially, and the maintenance therapy was continued with isoniazid and rifampicin for a minimum of 4 months. All the cases were followed-up at the TB dispensary and treated with directly observed treatment. The treatment response was evaluated according to clinical and US findings. Follow-up period was 2 years.

Main inclusion criterion was histopathologically proven "granulomatous disease of the breast" with noncaseating granuloma formation. The other inclusion criteria were i) women treated with nonspecific antibiotherapy (amoxicillin +clavulanic acid I gr $2 x$ l combined with ciprofloxacin 500 2xl/per day for two weeks) and steroids (30 mgr/day prednisolone for two weeks) with no treatment response, ii) prolonged symptoms and clinical-radiological findings, iii) recurrent symptoms and findings, iv) patient rejection to the major surgical approach.

Women with a diagnosis of TB mastitis ( $n=3$ ) (accurate diagnosis confirmed by histopathological and/or microbiological methods) were excluded.

\section{Statistical Analysis}

Descriptive statistical analysis was performed. All the statistical analysis were performed by using SPSS software version 24.0 (IBM SPSS Corp.; Armonk, NY, USA).

\section{RESULTS}

All the patients were fertile and gave birth to at least one child. Most of the patients had an uneventful period during and after pregnancy; however, breast induration and the nipple irritation history was declared during the lactational period in $4(20 \%)$ of patients.

None of the patients had a history of TB. Only two patients had a TB contact with their first-degree relatives, indicating household contact. Clinical characteristics of the patients are shown in Tablel. The median age at time of diagnosis was 34 years (range, 21-52). The major complaints were breast mass, pain, and nipple discharge. 


\begin{tabular}{|c|c|c|}
\hline $\begin{array}{l}\text { Patients with GM who received empirical } \\
\text { anti- tuberculosis treatment } n=20\end{array}$ & $\begin{array}{c}\text { Number of } \\
\text { Patients } \\
n\end{array}$ & $\begin{array}{l}\text { Percentage } \\
\%\end{array}$ \\
\hline History of TB & 0 & 0 \\
\hline Contact with TB & 2 & 10 \\
\hline $\begin{array}{l}\text { Symptoms } \\
\text { Isolated symptoms (mass/pain/ } \\
\text { nipple discharge) }\end{array}$ & 6 & 30 \\
\hline More than one symptom & 14 & 70 \\
\hline Suspicion of breast cancer & 9 & 45 \\
\hline \multicolumn{3}{|l|}{ Treatment response } \\
\hline Complete response & 20 & 100 \\
\hline Relapse & । & 5 \\
\hline \multicolumn{3}{|l|}{ Involvement of breast } \\
\hline Unilateral & 19 & 95 \\
\hline Bilateral & । & 5 \\
\hline Multifocal & 14 & 70 \\
\hline
\end{tabular}

Breast US revealed skin thickening and edema, mastitis, abscess formation, and suspicious lesions mimicking malignancy. Of the total, 19 (95\%) women had unilateral and I (5\%) had bilateral breast involvement. Fourteen (70\%) cases had unilateral multifocal involvement with no specific quadrant localization. In $9(45 \%)$ patients, breast carcinoma was highly suspected both clinically and radiologically. Wide local excision was the mainstay of both accurate diagnosis and surgical treatment, and it was performed in all the cases. Baseline clinical characteristics of patients are given in Table I.

Median time from the initiation of symptoms to the hospital admission was 7 days (range, I-364), and median time from admission to diagnosis was 4.5 months (range, I-120), indicating both a delay in admission and in initiating an appropriate treatment. Median number of health care centers admitted during diagnosis and treatment was 2.5 (range, I-4). Of the total, $75 \%$ were admitted to hospital in the first 60 days and $75 \%$ of patients were admitted to three different health care centers until the definitive diagnosis.

The median tuberculosis skin test results of the patients were 12 $\mathrm{mm}$ (range, l-20). None of the patients had active pulmonary or sequela radiological TB findings on the chest $X$-ray. All the histopathological examination of the surgical materials revealed "granulomatous disease of the breast" with noncaseating granuloma formation, destruction of the ductal structure, infiltration of the inflammatory cells, and micro-abscess formation. None of the specimens had a positive stain for acid-fast bacilli during the examination of the tissue samples. All the patients had complete response to standard treatment regimen. One patient had recurrence and re-treatment was started.

\section{DISCUSSION}

Among the 48 patients with GM, 28 were responders to the standard antibotic and steroid treatment, while the remaining 20 patients were treated with anti-TB succesfully and safely.
According to Guideline of Tuberculosis Treatment and Diagnosis published by the Turkish Ministry of Health in 2019, extrapulmonary TB is detected in 35\% of patients with the diagnosis of TB in Turkish population (5). Since 2003, active surveillance study of TB has been proceeded among hospitals in Ankara, and extrapulmonary involvement of TB cases is detected according to the data reports and close follow-up. According to our clinical experience and previous literature, difficulty in diagnosis is a common problem in these cases (6). Breast involvement of TB is a rare condition with an uncertain incidence. There were only 120 cases reported until 1999 (7). The incidence of the disease has been stated as less than $0.1 \%$ of all breast lesions in Western countries and $3-4 \%$ in TB endemic regions, such as India and Africa $(8,9)$. EZN stain, tuberculin skin test, and routine histopathological studies are sometimes not sufficient neither for ruling out nor for confirming the diagnosis of TB. A differential diagnosis including malignancy, nonspecific suppurative infections, fungal infections, or TB is required when mastitis with abscess formation, recurrence, and long duration of symptoms are present.

Clinically, patients present with a hard lump that mimics carcinoma, which may lead to nipple retraction and sinus formation $(I 0, I I)$. Radiologically and clinically, GM may be mistaken for breast cancer. Even mammographic and fine needle aspiration cytology findings may be misinterpreted as malignancy (I2).

It has been shown that GM is usually unilateral and may be located in all breast quadrants, except for the subareolar area (I3). In our study, most of the cases had unilateral involvement. Bilateral involvement was present in only one case. In previous studies, bilateral involvement has been reported in only a maximum of two patients (14). In their series, Velidedeoğlu et al. reported 10 cases with bilateral involvement and stated that bilateral GMs have a higher rate of relapse and resistance to medical treatment compared to unilateral GMs (I5).

According to the literature, most patients with GM are relatively young and fertile women ranging between II and 83 years; however, the disease usually is common in the third or fourth decade $(16,17)$. In our study, most of the cases were also young fertile females with a median age of 34 years at time of diagnosis. This finding is concordant with literature.

Some authors have suggested that GM is sometimes a self-limiting condition with duration of 2 to 24 months; however, a chronic presentation could last for several years (18). Furthermore, GM may have a progressive clinical course with multiple recurrences. Since it is a rare condition, it may lead to a delay in appropriate diagnosis and subsequent initiation of treatment. In our study, diagnostic period as well as initiation of treatment was prolonged due to factors caused by both patients and physicians. Apart from the nature of the disease, we think that there are mainly three factors leading to this situation: I) During the follow-up period, a high number of patients changed their health care centers 2) In most of the cases, fine needle aspiration biopsy (FNAB) was performed for histopathological diagnosis instead of wide local excision, which was the mainstay for both accurate diagnosis and surgical treatment. Since FNABs were not always diagnostic, multiple biopsies were performed, especially for the patients with a suspicion of malignancy. 3) Different therapeutic regimens including antibiotics, steroids, and abscess drainage were applied and physicians had 
to wait for the treatment response. We think that the delay in diagnosis and treatment of the disease caused either by physicians or patients is an important issue concerning granulomatous lesions of the breast. Delayed approach may lead to the destruction of the breast tissue, resulting ultimately with unnecessary mastectomies.

Up to date, there has been no clear consensus regarding the optimal treatment strategy in GM cases. As GM is a benign and non life-threatening disease, it is crucial to apply accurate and optimum regimen that will not lead to permanant deforming and serious side effects. Antibiotics, steroids, methotrexate (MTX), azathioprine, wound drainage, wide surgical excision, mastectomy, or close follow-up have been proposed (19-21).

In patients without a definitive diagnosis of TB both microbiologically and histopathologically, GM may be considered as an extrapulmonary involvement of TB in the breast. We think that in patients treated with nonspecific antibiotherapy/steroids with no response, and who had prolonged and recurrent symptoms with clinical-radiological findings, and finally in patients who rejected major surgical approaches, empirical antituberculosis treatment may be a choice. In our study, all the patients had a complete response to standard antituberculosis treatment with no side effects. Only one patient had a recurrence one year after completing the treatment due to low compliance to therapy. To our knowledge, there has been no previous report regarding antituberculosis treatment for GM.

Extrapulmonary TB can sometimes be presented as breast tuberculosis. However, difficulties in the differential diagnosis are frequently seen in GM/ breast TB patient groups. Suspicion of breast tuberculosis is essential among pathologically verified GM patients who are especially clinically nonresponders to GM treatment, with prolonged symptoms and recurrent findings.

We conclude that, clinical features with histopathologically proven GM can be a factor for the antituberculosis treatment choice, which is a safe and an effective approach. In addition to the surgical approaches, empirical antituberculosis treatment can be started in these groups of patients, particularly in developing countries with especially high-incidence regions for tuberculosis. In these groups of patients with diagnostic difficulty, new molecular tests may be recommended.

Ethics Committee Approval: Ethics committee approval was received for this study from the ethics committee of Ankara Oncology Research and Training Hospital (17/09.12.2017).

Informed Consent: All participants were provided written informed consent.

Peer-review: Externally peer-reviewed.

Author contributions: Concept - C..̈., F.D.A.; Design - T.Ö.; Supervision - T.Ö., M.H.T.; Resource - S.C.I., F.D.A.; Materials - Ç.Ö., F.D.A.; Data Collection and/or Processing - C..Ö., T.Ö., M.H.T.; Analysis and/or Interpretation - F.D.A., C..Ö.; Literature Search - C..Ö.; Writing - C..Ö.; Critical Reviews M.H.T., T.Ö.

Acknowledgements: The authors would like to thank health care workers of Turkish TB dispensaries and those who contribute to TB surveillance studies to provide public health overall the country.

Conflict of Interest: Authors have no conflicts of interest to declare.
Financial Disclosure: The authors declared that this study has received no financial support.

\section{REFERENCES}

I. Baslaim MM, Khayat HA, Al-Amoudi SA. Idiopathic granulomatous mastitis: a heterogeneous disease with variable clinical presentation. World J Surg 2007; 31(8): 1677-81. [Crossref]

2. Lai EC, Chan WC, Ma TK, Tang AP, Poon CS, Leong HT. The role of conservative treatment in idiopathic granulomatous mastitis. Breast J 2005; II(6): 454-6. [Crossref]

3. Imoto S, Kitaya T, Kodama T, Hasebe T, Mukai K. Idiopathic granulomatous mastitis: case report and review of the literature. Jpn J Clin Oncol 1997; 27(4): 274-7. [Crossref]

4. Guideline of Tuberculosis Diagnosis and Treatment published by Turkish Ministry of Health 20II. Accessed date: Jan 05, 2020. Available from: https://www.toraks.org.tr/uploadFiles/30102014133530-tuberkuloz_tani_ve_tedavi_rehberi.pdf

5. Guideline of Tuberculosis Diagnosis and Treatment published by Turkish Ministry of Health 2019. Accessed date: Jan 05, 2020. Available from: https://hsgm.saglik.gov.tr/depo/birimler/tuberkuloz_db/haberler/Tuberkuloz_Tani_Ve_Tedavi_Rehberi_/Tuberkuloz_Tani_ve_Tedavi_Rehberi.pdf

6. Bani-Hani KE, Yaghan RJ, Matalka II, Shatnawi NJ. Idiopathic granulomatous mastitis: time to avoid unnecessary mastectomies. The Breast Journal 2004; 10(4): 318-22. [Crossref]

7. Ayeva-Derman M, Perrotin F, Lefrancq T, Roy F, Lansac J, Body G. Idiopathic granulomatous mastitis. Review of the literature illustrated by 4 cases. J Gynecol Obstet Biol Reprod (Paris) 1999; 28(8): 800-7.

8. Luh SP, Chang KJ, Cheng JH, Hsu JD, Huang CS. Surgical treatment for primary mammary tuberculosis - report of three octogenarian cases and review of literature. Breast Journal 2008; 14(3): 3II-3I2. [Crossref]

9. Maroulis I, Spyropoulos C, Zolota V, Tzorakoleftherakis E. Mammary tuberculosis mimicking breast cancer: a case report. J Med Case Rep 2008; 2: 34. [Crossref]

10. Sakurai T, Oura S, Tanino H, Yoshimasu T, Kokawa Y, Kinoshita T, ef al. A case of granulomatous mastitis mimicking breast carcinoma. Breast cancer 2002; 9(3): 265-8

II. Cakir B, Tuncbilek N, Karakas HM, Unlu E, Ozyilmaz F. Granulomatous mastitis mimicking breast carcinoma. Breast J 2002; 8(4): 25I-2. [Crossref]

12. Rosen PP. Rosen's Breast Pathology. 3rd ed. New York: Lippincott Williams $\delta$ Wilkins; 2009.

13. Yilmaz E, Lebe B, Usual C, Balci P. Mammographic and sonographic findings in the diagnosis of idiopathic granulomatous mastitis. Eur Radiol 200I; II(II): 2236-40. [Crossref]

14. Pistolese CA, Di Trapano R, Girardi V, Costanzo E, Di Poce I, Simonetti G. An unusual case of bilateral granulomatous mastitis. Case Rep Radiol 2013; 2013: 694-7. [Crossref]

15. Velidedeoglu M, Kilic F, Mete B, Yemisen M, Celik V, Gazioglu E, et al. Bilateral idiopathic granulomatous mastitis. Asian J Surg 20l6; 39(I): 12-20. [Crossref]

16. Erhan Y, Veral A, Kara E, Ozdemir N, Kapkac M, Ozdedeli E, et al. A clinicopathologic study of a rare clinical entity mimicking breast carcinoma: Idiopathic granulomatous mastitis. Breast 2000; 9(I): 52-6. [Crossref]

17. Ocal K, Dag A, Turkmenoglu O, Kara T, Seyit H, Konca K. Granulomatous mastitis: clinical, pathological features, and management. Breast J 2010; 16(2): 176-82. [Crossref]

18. Garcia-Rodiguez JA, Pattullo A. Idiopathic granulomatous mastitis: a mimicking disease in a pregnant woman. BMC Res Notes 2013; 6: 95. [Crossref]

19. Yau FM, Macadam SA, Kuusk U, Nimmo M, Laeken NV. The surgical management of granulomatous mastitis. Ann Plast Surg 2010; 64(I): 9-16. [Crossref]

20. Sato N, Yamashita H, Kozaki N, Watanabe Y, Ohtsuka T, Kuroki S, et al. Granulomatous mastitis diagnosed and followed up by fine-needle aspiration cytology, and successfully treated by corticosteroid therapy: report of a case. Surg Today 1996; 26(9): 730-3. [Crossref]

21. Schmajuk G, Genovese MC. First report of idiopathic granulomatous mastitis treated with methotrexate monotherapy. J Rheumatol 2009; 36(7): 1559-60. [Crossref] 